\title{
A Ditadura na adaptação de Milagre na cela para o filme $A$ freira e a tortura
}

Dênis Sebastião Ramos Firmino; Instituto de Letras e Linguística da Universidade Federal de Uberlândia - Programa Pós-Graduação em Estudos Literários Uberlândia, MG; E-mail: <denisramosf@yahoo.com.br>.

\section{Resumo}

O trabalho tem como objetivo refletir a adaptação do texto teatral Milagre na Cela (1977) para o filme A freira e a tortura (1983), respectivamente produzidos pelo dramaturgo Jorge Andrade e pelo diretor de cinema Ozualdo Candeias. As obras estão contextualizadas no período da ditadura militar no Brasil. À luz dos estudos comparados de literatura com outras artes, objetivase elucidar como um texto teatral pode ser ressignificado ao ser adaptado para uma obra da sétima arte. Neste sentido, viabilizase a perspectiva de contar por outras óticas o contexto histórico que assolou a democracia no Brasil entre os anos de 1964 a 1985.

Palavras-chave: Literatura Comparada, Adaptação, Milagre na Cela, Jorge Andrade, A freira e a tortura, Ozualdo Candeias

É reconhecido que a história é construída por alicerces que são sustentados por distintas óticas, as quais são guiadas por interesses que organizam e narram os fatos em consonância com motivações peculiares de grupos, instituições ou culturas. Por outro lado, algumas histórias são silenciadas por não existir resquícios ou por não se ter acesso as fontes que poderiam elucidar uma época, como por exemplo, a era medieval.

A tendência de escrever a história ancorada na ideia de linearidade, cristaliza-se em poder perpetuar e em conferir superior relevância a alguns acontecimentos ou homens que estiveram inseridos em um contexto, enquanto que outros fatos e indivíduos são relegados ao esquecimento e posicionados à margem da trajetória de uma sociedade.

A história de uma civilização não é revelada em sua totalidade, sempre haverá a hipótese de ser complementada conforme 
exemplifica Weyne "[...] um livro de história surge com um aspecto muito diferente daquilo que parece ser; não se trata do Império Romano, mas daquilo que ainda podemos saber desse império" (Weyne, 1976: 45).

À luz da hipótese da história poder ser narrada e complementada por outras visões, torna-se legítimo imergir em fontes alternativas que contem e recontem os fatos por direções que desvelam informações e conhecimentos através de vozes que estão sobrepostas pelo anonimato. Exemplos de expressões em que há a capacidade de significar ou ressignificar recortes da história, podem ser encontradas em obras literárias e em obras cinematográficas que realizam uma linha marginal perante o que é firmado como canônico.

Outro exemplo de movimento em que também pode ser verificado o propósito de clarificar o que realmente aconteceu no passado, é a Comissão Nacional da Verdade. As atividades da CNV estão em sintonia com a ideia que se instalou no século XX de se observar a história por outros ângulos.

Questionar e averiguar as verdades até então formuladas sobre o período do regime militar, é uma das dinâmicas que promovem a leitura do passado e o faz ser modificado com as lentes do presente. Nisto, à luz de pareceres que irrompem através dos depoimentos, relatos, testemunhos e apurações, germina 0 ato de recontar a história e oportunizar aos indivíduos interpretações para preencher lacunas, isto é, agir feito um leitor ativo que

[...] advinha o lugar das lacunas mal preenchidas, não ignora que o número de páginas concedidas pelo autor aos diferentes momentos e aos diversos aspectos do passado é uma média entre a importância que estes aspectos têm a seus olhos e a abundância da documentação; sabe que os povos denominados sem História são simplesmente povos cuja História se ignora e que os primitivos têm um passado como todo mundo. (Weyne, 1976: 46)

Alinhado ao que está exposto acima, ao se recorrer a uma arte como a literatura ou como o cinema, estas proporcionam ler a 
realidade a partir de variados cenários. Estas possibilidades de leituras e de escrita da história são tão válidas quanto às interpretações sobre a história social que é transmitida em instituições de ensino.

A literatura está em harmonia com a história não apenas pelo fator da narrativa, mas também por fomentar elucidações de um contexto. Redigir uma obra, não significa que a mesma será portadora da expressão de uma realidade em toda a sua plenitude, mas aventa a oportunidade de estabelecer uma imagem de um fato social para gerar construções de sentidos em torno do mesmo.

A qualidade da literatura em diversificar caminhos para abordar a história, é uma herança ofertada pelo amadurecimento dos estudos comparados de literatura. A partir do surgimento de teóricos oriundos da escola americana de literatura comparada, os limites impostos pelas escolas do centro europeu se esfacelaram, tornando viável a implementação de críticas ao modelo de comparação de escolas europeias como a da França e a da Inglaterra. Para René Wellek

A literatura comparada surgiu como uma reação contra o nacionalismo limitado de muitos estudos do século XIX, como um protesto contra o isolacionismo de muitos historiadores da literatura francesa, alemã, italiana, inglesa, etc. (Wellek, 1994: 112)

O combate contra a demarcação de fronteiras estava explícito ao rejeitar o entendimento que havia sobre literatura "comparada" e literatura "geral". Posições que fincam marcos não agregavam exatamente por

[...] toda a concepção de áreas cercadas por placas de não ultrapasse deve ser rechaçada por uma mente aberta. Tal concepção só pode surgir dentro dos limites da metodologia obsoleta preconizada e praticada pelos teóricos clássicos da literatura comparada que supõem que os fatos devem ser descobertos como pepitas de ouro e que podemos exigir nossos direitos de garimpeiros sobre eles. (Wellek,1994: 116).

Obras consideradas não canônicas começaram a serem incluídas nas pesquisas de literatura comparada, vide a 
apreciação de textos que se encontravam à margem do universo da academia, como os textos teatrais, já que estes, também permitem fornecer recortes dos panoramas sociais e políticos de uma sociedade.

$\mathrm{Na}$ literatura brasileira, textos teatrais como Ponto de Partida de Gianfrancesco Guarnieri, Papa Highirte de Oduvaldo Vianna Filho, Torquemada de Augusto Boal, O Abajur Lilás de Plínio Marcos e Milagre na Cela de Jorge Andrade, são algumas das obras teatrais que retrataram e debatem os anos em que os arbítrios dos militares assolaram a democracia no Brasil.

Dentre os textos supracitados, a tônica deste trabalho será a obra Milagre na Cela e a adaptação desta para o filme $A$ freira e a tortura, respectivamente do dramaturgo Jorge Andrade e do cineasta Ozualdo Candeias.

Predomina nos textos de Jorge Andrade a ficcionalização da decadência das elites rurais e urbanas paulistas, sendo o trabalho com a memória o fio condutor para a redação de suas peças, as quais, em sua maioria, estão na coletânea Marta, a árvore e o relógio de 1970, porém, ao publicar em 1977 o texto de Milagre na Cela, Andrade direcionou sua arte para abordar um contexto que estava no presente.

Milagre na Cela é uma das obras de Andrade que suscitam reflexões sobre contextos em que a tortura ocupava papel central para oprimir indivíduos considerados subversivos pela ditadura. Na dramaturgia de Andrade, a questão da tortura não é somente debatida por Milagre na Cela, mas esta peça também possui intertextualidade com a peça $O$ Incêndio. Esta abordagem é corroborada por Andrade ao conceder entrevista ao Jornal do Brasil em 1981: "[...] eu escrevi Milagre na Cela e O Incêndio, ambas tratando do problema da tortura." (Azevedo et al, 2012: 158)

O trabalho de ecoar vozes para significar e ressignificar a temática da tortura no regime militar, pode também ser 
verificado na produção cinematográfica brasileira que foi realizada durante a ditadura.

Em 1983, o diretor de cinema Ozualdo Candeias, "[...] facilmente o cineasta mais desconhecido de nossa história recente." (Gardnier, $s / n)^{1}$, adaptou, com elementos do Cinema Marginal$^{2}$, o texto de Milagre na Cela que inspirou o filme $A$ freira e a tortura. Nesta película, os principais personagens são interpretados por Vera Gimenez e David Cardoso, atores ícones da pornochanchada.

O exercício de analisar em programas de pós-graduação, um texto teatral e a sua adaptação para a sétima arte, pode ser creditado ao advento das pesquisas e dos textos da escola americana de literatura comparada, na qual houve 0 entendimento de comparar uma obra literária com outras áreas do conhecimento.

No Brasil, principalmente ao se fundar a ABRALIC (Associação Brasileira de Literatura Comparada), juntamente com a adesão aos estudos culturais, ocorreu a difusão de novos diálogos da literatura comparada para com diferentes áreas, o que propiciou o intercâmbio de produções entre pesquisadores brasileiros e estrangeiros. Esta dinâmica, garantiu a pluralização dos estudos e o reconhecimento de obras que não estavam contempladas na esfera do cânone ocidental, mas que estavam à margem das pesquisas, como: os discursos das

1 A citação foi extraída do site: http://www.contracampo.com.br/25/sabersobreozualdo.htm

2 Filmagens em favelas, bordéis, inserção de indivíduos marginalizados e cenas de realismo grotesco, são alguns dos elementos que caracterizam os filmes do Cinema Marginal. 
minorias sexuais, étnicas e de gênero e também da cultura das bordas $^{3}$.

Estas transformações da literatura comparada no Brasil agregaram distintas expressões para a formulação de conhecimentos e também está vinculada a percepção de reler a história por novos horizontes. São evidências que não se dissociam do fenômeno da globalização que acelerou as formas de contato, acelerou a intercambiação de informações e conferiu imediatismo e maior proximidade nas formas de se conviver socialmente.

$\mathrm{Na}$ urgência de estabelecer estruturas de vida que compactuem com uma vida mais intensa, está a eclosão de manifestações configuradas por características semióticas e pela utilização fluente da imagem. Estas expressões impulsionam a arte literária em se relacionar com artes provindas do recurso audiovisual, como o cinema. Com isto, inaugura-se a possibilidade da literatura comparada em trabalhar com outras manifestações artísticas, inclusive as que se caracterizam por estarem localizadas em uma linha marginal de expressão, conforme realça Eneida Maria de Souza
A abertura para os estudos de ordem mais especificamente cultural representa uma ampliação do horizonte comparatista na atualidade, por descentrar o lugar hegemônico ocupado pela literatura e por avançar no sentido de introduzir novos termos na comparação. (Souza, 1997: 49).

Ao evocar a palavra marginal, contempla-se as obras que norteiam este trabalho, ou seja, o texto teatral Milagre na Cela e o filme $A$ freira e a tortura. Os textos teatrais, apesar de não estarem em uma posição de destaque nos estudos de literatura comparada, são instrumentos para representar oposições

\footnotetext{
${ }^{3} \mathrm{~A}$ denominada cultura das bordas, termo cunhado por Jerusa Pires Ferreira, contemplam obras como: Coleção Sabrina, Diários de um Banana e Literatura de Cordel.
} 
frente a regimes que cerceiam direitos sociais e constitucionais. Exemplo disso no Brasil, foi a atuação de dramaturgos e atores perante o golpe civil militar que vigorou de 1964 a 1985 . Unidos a músicos, cineastas, intelectuais e grupos de resistência à ditadura, a classe teatral enfrentou censuras e hostilidades as montagens e aos textos produzidos nos anos de chumbo.

Sobre Milagre na Cela que se constituiu em uma nova abordagem de Andrade para trabalhar com temáticas situadas na atualidade, Décio de Almeida Prado declarou em 13 de Julho de 1977 à Folha de São Paulo que:

Milagre na Cela talvez seja a melhor peça de Jorge Andrade. Formalmente, mostra que a técnica tradicional, baseada na palavra, na personagem, no enredo não se acha esgotada, como muitos pensam. Enquanto o conteúdo fala sobre o Brasil atual, sobre os problemas dos direitos humanos, mas sem a demagogia ou radicalismos. Encara a realidade no que tem ela às vezes de mais cruel, porém sabendo criar, ao mesmo tempo uma atmosfera de total confiança no homem. (Azevedo et al., 2012: 106)

Ao vivenciar os anos da ditadura e ao tomar conhecimento de casos verídicos de mulheres que foram aprisionadas e torturadas no regime militar, Andrade elaborou um enredo que expressa o esforço da personagem irmã Joana de Jesus Crucificado para provar a sua inocência perante o personagem do delegado Daniel.

Em 1981, ao ser entrevistado pela escritora Edla Von Steen, Andrade relata:

Eu juntei a experiência de quatro pessoas que conheço. Mulheres: duas religiosas e duas educadoras, que foram presas por suas idéias e seu modo de encarar a vida, a nossa realidade. E mesmo por causa de suas posições educacionais, pedagógicas. Foram presas e torturadas, como se fossem subversivas. Eu juntei então, a experiência das quatro e construí uma única personagem, que é a Irmã de Jesus Crucificado. Milagre na Cela é a experiência dela na prisão, a sua resistência à tortura, a resistência à repressão e à violência, marcando um momento do homem brasileiro (Azevedo et al., 2012: 154).

A trama apresenta o contexto de opressão imposto à irmã Joana pelo carcereiro Cícero e pelo delegado Daniel. Por 
exercer atividades como educadora de crianças, a freira é acusada de praticar atos subversivos. Torturas de natureza física, verbal e sexual são os elementos que fazem estabelecer a ênfase nas relações de poder ao longo do texto. Nos diálogos e nas torturas, Joana e Daniel desafiam um ao outro para obrigar quem cederá primeiro ao embate desenvolvido entre ambos, o que remonta à afirmação Michel Foucault que: "A tortura para fazer confessar tem alguma coisa de inquérito, mas também tem de duelo" (Foucault, 2008: 37).

No decorrer da obra, destacam-se no texto as mudanças de posições entre Joana e Daniel, ou seja, o delegado que antes torturava passa a ser torturado psicologicamente pela freira, pois devido as constantes violências sexuais, Daniel se apaixona por Joana, o que gera uma intensa fixação por ela e culmina numa instabilidade emocional, que está representada em um primeiro momento no espaço da cadeia e logo após na convivência com a família dele.

O texto de Jorge Andrade realça não apenas a relação entre a freira e o delegado, mas também prioriza a cumplicidade estabelecida entre Joana e a sua colega de cela, a prostituta Jupira. A prostituta ao perceber que Joana não teria condições físicas e psicológicas para suportar o ambiente do cárcere, passa a fornecer dicas para que a freira resista às violências e pressões pelas quais seria vítima. Esta solidariedade de Jupira para com Joana, além de criar amizade entre ambas, ensina a freira a como seduzir Daniel.

Essa relação que representa o encontro entre sagrado e o profano é um dos binarismos presentes no texto da peça, como também a relação entre torturador e torturado, realidade e ficção, dominação e submissão, prazer e dor, horror e sublime, dentre outras relações que podem surgir ao analisar o texto de Andrade.

Há também a retratação de discursos e situações que acrescentam lirismo e afeto na intenção de expressar que 
mesmo em um espaço de reificação do ser humano como é uma cadeia, é cabível a presença do sublime. Essa existência do belo é configurada por versos de poemas que estão estampados nas paredes da cela em que está Joana. São os poemas que propiciam energia para enfrentar e resistir às coerções impostas.

Milagre na Cela é uma obra que possibilita formar um retrato da época do regime militar, pois discute questões como a perseguição das autoridades aos cidadãos considerados subversivos, relações de poder, autoritarismo e valores cultivados pelo regime como a preservação de instituições como a família.

O cultivo aos bons valores que estavam ligados à questão da família, em um primeiro momento, pode estar ilustrado no texto pela relação cordial de Daniel com a esposa e com o filho dele. Entretanto, esta cordialidade se dissipa no decorrer da trama, devido ao fato de 0 delegado se desestabilizar emocionalmente, o que acarreta em agressões à Marina, esposa de Daniel. A casa do delegado que incialmente se constitui como um espaço feliz, onde a intimidade com a família possibilita momentos de sonhos, de sublimações e de devaneios, posteriormente passa a possuir uma atmosfera em que a violência se instaura. Nisto, pode-se inferir que Andrade, fornece conotações irônicas à relação de Daniel com a família, o que contraria os bons valores pregados pela ditadura.

Sublinha-se também o elo de afeição construído entre Joana e o preso Miguel, principalmente pelo fato da freira ter costurado para ele uma fronha, já que esta era sonhada por Miguel. No texto, Miguel jamais tinha tido uma morada, uma família, e é a fronha, peça concreta que pertence a uma casa, que materializa a possibilidade de viver em um lar.

As circunstâncias e os cenários com os quais Andrade compôs Milagre na Cela, estão na obra com o propósito de exercer tensão e criar artifícios que movam o olhar não somente para 
as personagens, mas para a desumanidade que reveste requintes como o da tortura. Antonio Candido ressalta que "O grande personagem desta peça talvez não seja nenhum dos figurantes, apesar da sua grande força; mas a tortura, abordada pela primeira vez entre nós como um fato com o qual é preciso conviver" (Andrade, 1977: 09). ${ }^{4}$

Ainda que não estejam em evidência nos estudos literários, é inerente aos textos teatrais a propriedade de realizarem um recorte da realidade para representarem em variados estilos os fatos que situam o homem na história. Em Milagre na Cela, as mazelas do autoritarismo estão denunciadas por personagens subjugados pelo domínio de um sistema que ceifa a liberdade, porém, é a conduta destes indivíduos marginalizados que concebem a conditio sine qua non do teor humano na dramaturgia de Jorge Andrade

Só entendo o teatro como representação viva de um fato e neste fato o principal personagem deve ser sempre 0 homem. O homem brasileiro. Acho que arte que não registra o homem, no tempo e no espaço, para mim não é arte, não é teatro, não é literatura, não é nada. As gerações futuras vão querer saber como o homem brasileiro pensava, como vivia, como trabalhava, como lutava. Penso que esta é a missão principal, essencial, da arte e do teatro (Azevedo et al.,2012: 154).

Mesmo tendo sofrido perseguições por causa da censura, o texto de Andrade manteve seu caráter incisivo e cortante ao produzir efeitos para alertar a necessidade de observar o passado e legitimar a importância social de peças de resistência, colocando-as em movimento através de novas montagens e estimulando, no presente, olhares lúcidos para assimilar como a história pode ser reescrita por perspectivas que flutuam por discrepantes veredas.

${ }^{4} \mathrm{~A}$ citação que se refere a Antônio Candido foi extraída do prefácio do texto da peça teatral Milagre na Cela. 
O cinema nacional também produziu filmes que evocam o trabalho de contestar os anos em que o Brasil esteve à mercê dos militares. Juntamente com artistas que estavam engajados para elaborar obras de repúdio ao regime político da época, o cineasta Ozualdo Candeias também fez coro com a classe artística para apontar no filme $A$ freira e a tortura, as violências acometidas aos cidadãos considerados subversivos.

Candeias foi um diretor que privilegiou o tecer de obras cinematográficas que narram histórias de pessoas que se localizam em contextos marginais em que a miséria, a exclusão e a violência acompanham o cotidiano dos cidadãos.

Ao se analisar $A$ freira e a tortura, apreende-se que um dos pontos que convergem do texto de Milagre na Cela para o filme de Candeias, é o fato de que a ditadura militar é representada pela polícia civil, esta encarnada no personagem do carcereiro e do delegado, porém este no texto da peça possui o nome de Daniel e no filme possui o nome de Rui. Coincide também a relação de poder estabelecida entre a freira e o delegado, na qual a tortura sexual despertará em ambos um clima de sedução. Cenas do final do filme estão de encontro com o final do texto da peça, na qual Daniel é estrangulado e morto pelo preso Miguel, e após isto, Joana é libertada da prisão. No filme também há o estrangulamento e morte do delegado Rui, mas no final Joana e Rui, aparecem nus e caminham de mãos dadas, fornecendo significados como o de transgressão, ou seja, despidos de toda a bagagem de valores que o contexto político da época pregava como correto.

Entre algumas oposições de $A$ freira e a tortura para Milagre na Cela, estão a não gravidez de Joana na obra de Candeias e também a não retratação do elo de intimidade construído através da amizade entre a prostituta Jupira e a freira. $O$ espaço do convento é pouco explorado no filme, já que na peça de Jorge Andrade, o bispo e as demais freiras estão em constantes diálogos referentes à prisão de Joana. 
No filme, diferentemente do texto de Andrade, os diálogos entre as personagens são breves, desse modo, não há confrontos de discursos devido a uma valorização do impacto da imagem, principalmente as que remetem a exploração de cenas com corpos nus.

Em $A$ freira e a tortura há também cenas de sexo não explícito, além de cenas contornadas por realismo grotesco, na qual se retratam personagens coadjuvantes marcados por fealdade e anti-erotismo. Esta síntese de passagens mencionadas, ilustram como o olhar de um diretor é capaz de ressignificar sentidos ao adaptar uma linguagem textual para uma linguagem imagética.

Obras literárias e da sétima arte podem apresentar um conjunto de leituras dissonantes sobre determinado contexto histórico, de modo que consiga burlar censuras ou qualquer outra forma de cerceamento. Se na ditadura foi proibido se manifestar contra o regime, é nas artes que o repúdio ao autoritarismo tomou impulso, como na escrita de um dramaturgo ao contar por seu texto o drama da tortura ou por um diretor de cinema que ficcionalizou por meio de seu processo criativo as vivências dos que tiveram as vozes silenciadas pelo golpe civil militar.

A experiência de comparar um texto literário com outra forma de expressão artística, principalmente em obras que não são prestigiadas como canônicas, é uma das prerrogativas proporcionadas pelo amadurecimento das compreensões sobre o que é realizar literatura comparada.

A partir do amadurecimento citado acima, torna-se possível ler os acontecimentos de forma que apenas um lado da história não prevaleça como detentora da verdade. A veemência da versão dos que se creditam como vencedores pode ser conferida a um intrínseco anseio de reverberar saberes que reproduzam o controle de camadas e de circunstâncias que estão reféns da hegemonia de alguns. 
É necessário que haja uma descontinuidade, ou seja, examinar a história e o percurso histórico da literatura comparada a contrapelo. Há a missão de deslocar o olhar no intuito de enveredar por caminhos que permitam descobrir as membranas permeáveis de memórias e obras que clamam a emergirem de um passado ou de um anonimato não totalmente explorado, investigado e evidenciado em todas as suas faces.

Ao se nortear por reflexões que não estejam condicionadas a conceitos caracterizados como inquestionáveis e supremos, privilegia-se uma ruptura que auxiliará a novas descobertas dedicadas a fornecer voz aos que estão marginalizados e excluídos, além de desencadear compreensões alternativas de um mesmo acontecimento. Esta dinâmica instaurará cruzamentos, trocas e migrações de conhecimentos na esfera do aprimoramento dos estudos e de esclarecimentos que importam à coletividade social.

Neste sentido, uma maior abertura dos estudos literários tornará ainda mais possível pluralizar os diálogos e moldar reflexões com uma visão universal perante a diversidade de produções que há no terreno das artes, principalmente por desenvolver considerações que levem a se posicionar acerca de questões como o etnocentrismo.

É necessário reforçar a descolonização nos estudos da literatura, no intuito de negar óticas a partir de uma ideia de tradição e, desse modo, garimpar obras que possam ensejar interessantes leituras e releituras da história e que não se restrinjam a um bloco único de expressões literárias, como as obras-primas.

\section{Referências}

A FREIRA E A TORTURA (1983). Direção de Ozualdo Candeias. Brasil.DVD (85 min.), NTSC, son., color.

Andrade, J. (1977). Milagre na Cela. Rio de Janeiro: Paz e Terra. 
Andrade, J. (1981) . Jorge Andrade 90 anos: (Re) leituras - Volume 1 : A Voz de Jorge (2012). Azevedo, E. A., Martins, F., Neves, L. O., Viana, F. São Paulo: FAPESP, 139-156. Entrevista concedida a Edla Von Esteen.

(1981). Jorge Andrade 90 anos: (Re) leituras Volume 1: A Voz de Jorge (1977). Azevedo, E. A., Martins, F., Neves, L. O., Viana, F. São Paulo: FAPESP, p. 157-159. Entrevista concedida ao Jornal do Brasil.

Arantes, L. (2009). Entre o texto e a tela: Apontamentos acerca de Milagre na Cela de Jorge Andrade e A freira e a tortura de Ozualdo Candeias. Revista ouvirOUver, Uberlândia, 5, 76-83.

Foucalt, M. (2008). Vigiar e Punir: História da violência nas prisões.Trad. Raquel Ramalhete. Rio de Janeiro: Vozes, 37.

Gardnier, R. . O que há para saber sobre Ozualdo Candeias. Retirado website http://www.contracampo.com.br/25/sabersobreozualdo.htm .

Souza, E. ; Miranda, W. (1997). Perspectivas da literatura comparada no Brasil. In: Carvalhal, T. (org.). Literatura comparada no mundo: questões e métodos. Porto Alegre: L\&PM/VITAE/AILC, 39-52.

Wellek, R. (1994). A crise da literatura comparada. In: Coutinho, E; Carvalhal, T. (org). Literatura comparada: textos fundadores. Rio de Janeiro: Rocco, 108-120.

Weyne, P. (1976). Tudo é histórico, portanto a história não existe In: Silva, M. (org.) Teoria da História. São Paulo: Cultrix, 45-56. 